Case Report

\title{
A Rare Case of Lateral Canthal Gouty Tophus Presenting as an Eyelid Mass
}

\author{
Austin S. Nakatsuka, ${ }^{1}$ Timothy F. McDevitt, ${ }^{2}$ and Pamela S. Tauchi-Nishi ${ }^{3,4}$ \\ ${ }^{1}$ University of Hawaii John A. Burns School of Medicine, Honolulu, HI, USA \\ ${ }^{2}$ Department of Surgery, University of Hawaii John A. Burns School of Medicine, Honolulu, HI, USA \\ ${ }^{3}$ Department of Pathology, University of Hawaii John A. Burns School of Medicine, Honolulu, HI, USA \\ ${ }^{4}$ Queen's Medical Center, Honolulu, HI, USA
}

Correspondence should be addressed to Austin S. Nakatsuka; austin32@hawaii.edu

Received 31 July 2016; Revised 24 September 2016; Accepted 13 October 2016

Academic Editor: Kostas G. Boboridis

Copyright (C) 2016 Austin S. Nakatsuka et al. This is an open access article distributed under the Creative Commons Attribution License, which permits unrestricted use, distribution, and reproduction in any medium, provided the original work is properly cited.

\begin{abstract}
A 41-year-old man with a history of gout presented with an enlarging eyelid growth. Clinical examination revealed a mildly indurated nodule at the lateral canthus. Following resection, histopathological examination revealed needle-shaped, crystalline material surrounded by multinucleated giant cells, findings consistent with gouty tophus. This represents just the sixth case of gouty tophus of the eyelid reported in the literature.
\end{abstract}

\section{Introduction}

Gout is a complex disorder characterized by elevated levels of monosodium urate. Deposition of urate crystals in joint soft tissues can lead to a chronic inflammatory reaction producing debilitating deformities called tophi [1]. While tophi more commonly occur in the digits, ear pinna, prepatellar bursa, and olecranon, they very rarely occur around the eye [1-3]. Unusual cases of urate crystal deposition in the cornea, orbit, iris, and anterior chamber have been described in the literature [4-6]. We report an unsuspected case of gouty tophus involving the lateral canthus of the eyelid. To our knowledge, this is only the sixth case of gouty tophus of the eyelid reported in the literature. All patient information and images presented in this case report have been deidentified in accordance with the Health Insurance Portability and Accountability Act guidelines.

\section{Case Report}

A 41-year-old man with a medical history significant for congestive heart failure presented with a gradually enlarging growth of the right outer lid. The growth had developed continuously over 1 year and was now becoming mildly irritating and pruritic although it remained painless. Previous ophthalmic history was unremarkable.

The patient had a 10-year history of gout treated with daily allopurinol and colchicine as needed for periodic attacks. The patient revealed that he had a gouty mass on his ankle and another nodule on his toe. A subsequent uric acid level was elevated at $10.4 \mathrm{mg} / \mathrm{dL}$. Family history was negative for gout.

On examination, visual acuity was 20/30-1 OU. Slit lamp examination revealed $2+$ dermatochalasis with steatoblepharon and a white subcutaneous, mildly indurated nodule $(4 \times 7 \times 4 \mathrm{~mm})$ at the lateral canthus of the right eye. On clinical appearance, the mass was suspected to be a simple epidermal inclusion cyst. Examination of the conjunctiva, cornea, anterior chamber, and pupils demonstrated no abnormalities. Resection of the canthal tumor at the lateral palpebral raphe with subsequent periramal repair was done. The specimen was fixed in formalin and submitted for histopathological examination.

\section{Histopathological Examination}

Gross examination of the formalin-fixed specimen revealed skin with an underlying cystic structure $(4 \times 4 \mathrm{~mm})$ containing soft white material. Histologic examination revealed 
TABLE 1: Case reports of eyelid and canthal tophi.

\begin{tabular}{lcccccc}
\hline Reference & $\begin{array}{c}\text { Patient age } \\
\text { (years) }\end{array}$ & $\begin{array}{c}\text { Duration of } \\
\text { gout (years) }\end{array}$ & $\begin{array}{c}\text { Duration of } \\
\text { lesion } \\
\text { (months) }\end{array}$ & Lesion location & $\begin{array}{c}\text { Lesion size } \\
(\text { MM) }\end{array}$ & Other lesions \\
\hline De Monteynard et al. (1986) [7] & 62 & - & - & Lateral canthus & - & - \\
Morris and Fleming (2003) [8] & 44 & - & 12 & R lateral canthus & $6 \times 5 \times 4$ & - \\
Yen et al. (2005) [2] & 27 & 3 & 3 & R medial canthus & $11 \times 5 \times 5$ & L first metatarsal \\
Jordan et al. (2008) [9] & 68 & 20 & 24 & L medial canthus & $5 \times 6 \times 4$ & L elbow, R elbow \\
Yang et al. (2008) [10] & 64 & & 108 & $\begin{array}{c}\text { L middle superior } \\
\text { eyelid }\end{array}$ & $13.9 \times 9.4 \times 7.6$ & - \\
Our patient & 41 & 10 & 12 & R lateral canthus & $4 \times 7 \times 4$ & Ankle, toe \\
\hline
\end{tabular}

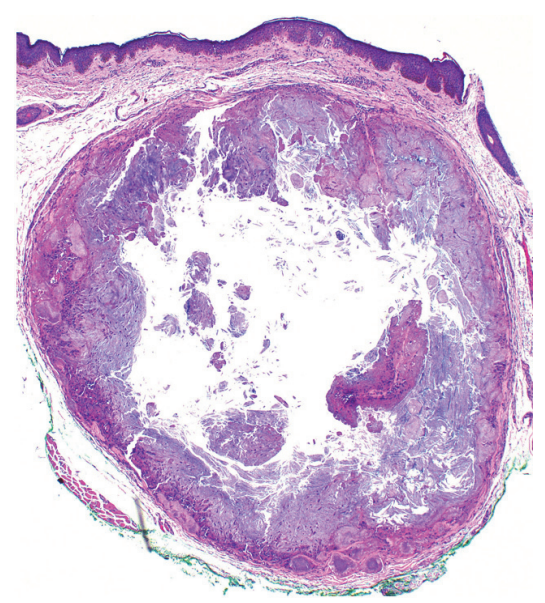

FIGURE 1: Light microscopic view of eyelid skin section demonstrating granulomatous reaction surrounding cavity of cystic structure containing crystalline material (hematoxylin-eosin stain, $\times 4$ ).

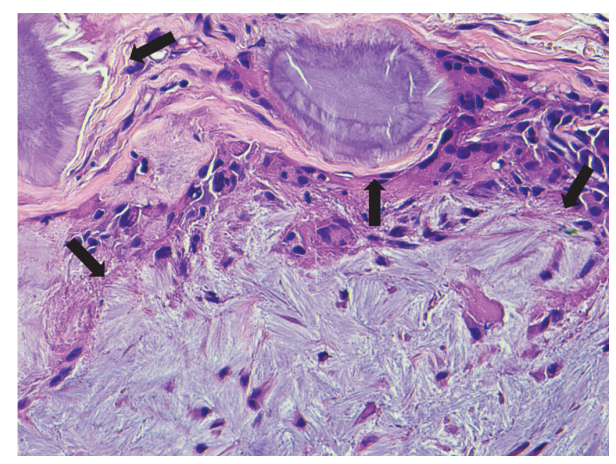

FIgURE 2: Histiocytes and multinucleated giant cells adjacent to urate crystals (arrows) with parallel, needle-like spokes in a radial pattern (hematoxylin-eosin stain, $\times 20$ ).

eyelid skin with dermal deposits of amorphous eosinophilic material surrounded by a foreign body granulomatous reaction (Figure 1). Higher power magnification revealed needleshaped, crystalline material surrounded by multinucleated giant cells and histiocytes (Figure 2).

\section{Discussion}

The appearance of ocular tophi is one of many ocular abnormalities that can occur in patients with gout. Rare cases have been reported of urate crystal deposition in the conjunctiva, sclera, corneal stroma and epithelium, anterior chamber, and iris [11]. A study by Ferry et al. reported that the most common ocular complication of gout is chronic bilateral ocular redness caused by conjunctival/episcleral hyperemia [4]. Lin et al. found that gout can lead to subconjunctival vesicles, subconjunctival hemorrhage, and scleral vascular tortuosity [11]. Very rare reports of uveitis due to gout have also been reported [4]. Elevated intraocular pressure has been claimed to be more prevalent in gout patients but little evidence has emerged to support it [4].

A literature search revealed only five prior cases of tophi in the eyelid or canthi (four at the medial/lateral canthi, one in the superior eyelid) reported between 1986 and 2008 (Table 1) [2, 7-10]. Documented in the French language, De Monteynard et al. described a case of a lateral canthus tophus in a 62-year-old patient that had the clinical appearance of a chalazion [7]. In the English literature, all cases of eyelid tophi were painless masses with no discharge, inflammation, or bleeding. These patients had previous histories of gout ranging from 3 to 20 years, with tophi presentation in areas such as the elbows and first metatarsal. Morris and Fleming encountered a right lateral canthal tophus developing over 1 year in a 44-year-old patient [8]. Yen et al. noted a right medial canthal tophus developing over 3 months in a 27-yearold patient [2]. Jordan et al. reported a case of left medial canthal tophus growing slowly over 2 years in a 68 -yearold patient [9]. Yang et al. described a tophus in the middle superior eyelid enlarging over 9 years in a 64-year-old patient [10]. In the case described by Jordan et al. the tophus was skincolored and resembled a basal cell carcinoma, based on the appearance of central depression and superficial crusting [9]. In contrast, the cases reported by Yang et al. and Morris and Fleming were yellow subcutaneous masses $[8,10]$. Yen et al. described their tophus case as a chalky, white mass [2]. Our case presented as a white subcutaneous mass resembling an epidermal inclusion cyst. Despite the rarity in presentation, gouty tophi should be considered in the differential diagnosis of periocular masses in patients with a history of gouty lesions, especially if located within the canthi. 


\section{Disclosure}

This article complies with HIPAA regulations.

\section{Competing Interests}

The authors have no financial or competing interests to disclose.

\section{References}

[1] V. Kumar, A. K. Abbas, and N. Fausto, Eds., Robbins and Cotran Pathologic Basis of Disease, Elsevier Saunders, Philadephia, Pa, USA, 7th edition, 2005.

[2] C. C. Yen, Y. H. Yi, and L. Ma, "Medial canthal tophus associated with gout," American Journal of Ophthalmology, vol. 140, no. 3, pp. 542-544, 2005.

[3] L. J. Forbess and T. R. Fields, "The broad spectrum of urate crystal deposition: unusual presentations of gouty tophi," Seminars in Arthritis and Rheumatism, vol. 42, no. 2, pp. 146-154, 2012.

[4] A. P. Ferry, A. Safir, and H. E. Melikian, "Ocular abnormalities in patients with gout," Annals of Ophthalmology, vol. 17, no. 10, pp. 632-635, 1985.

[5] N. C. Topping, A. Cassels-Brown, A. Chakrabarty et al., "Uric acid crystals presenting as an orbital mass," Eye, vol. 17, no. 3, pp. 427-429, 2003.

[6] M. Coassin, O. Piovanetti, W. J. Stark, and W. R. Green, "Urate deposition in the iris and anterior chamber," Ophthalmology, vol. 113, no. 3, pp. 462-465, 2006.

[7] M. S. De Monteynard, J. Jacquier, F. Adotti, and E. BodardRickelman, "Gouty tophus of the eyelid," Bulletin des Societas d'Ophtalmologic de France, vol. 86, no. 1, pp. 53-54, 1986.

[8] W. R. Morris and J. C. Fleming, "Gouty tophus at the lateral canthus," Archives of Ophthalmology, vol. 121, no. 8, pp. 1195-1197, 2003.

[9] D. R. Jordan, M. J. Belliveau, S. Brownstein, T. McEachren, and M. Kyrollos, "Medial canthal tophus," Ophthalmic Plastic and Reconstructive Surgery, vol. 24, no. 5, pp. 403-404, 2008.

[10] C. C. L. Yang, M. R. Vagefi, D. Davis, N. Mamalis, R. L. Anderson, and J. McCann, "Gouty tophus of the upper eyelid," Ophthalmic Plastic and Reconstructive Surgery, vol. 24, no. 5, pp. 404-406, 2008.

[11] J. Lin, G.-Q. Zhao, C.-Y. Che, S.-S. Yang, Q. Wang, and C.-G. $\mathrm{Li}$, "Characteristics of ocular abnormalities in gout patients," International Journal of Ophthalmology, vol. 6, no. 3, pp. 307311, 2013. 


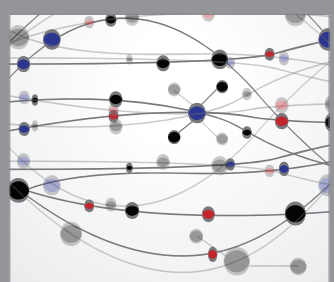

The Scientific World Journal
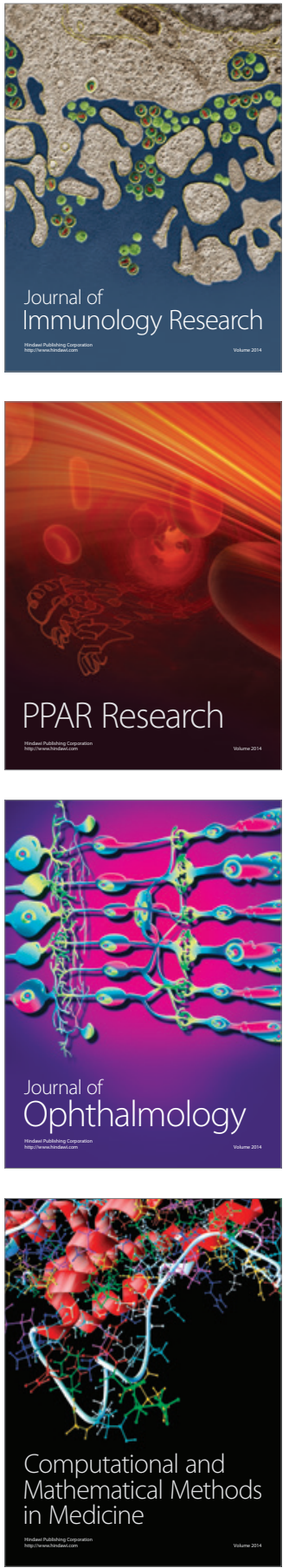

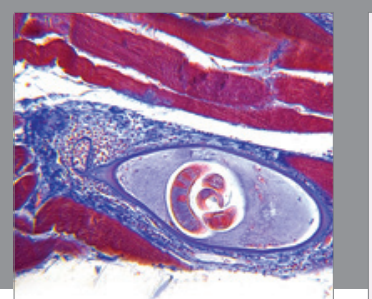

Gastroenterology Research and Practice

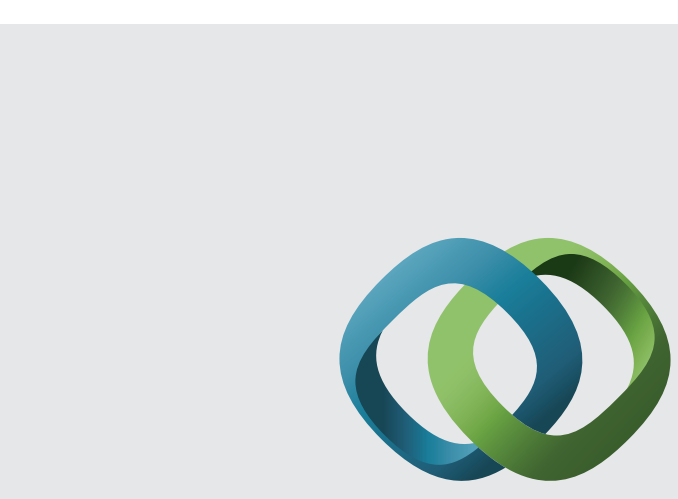

\section{Hindawi}

Submit your manuscripts at

http://www.hindawi.com
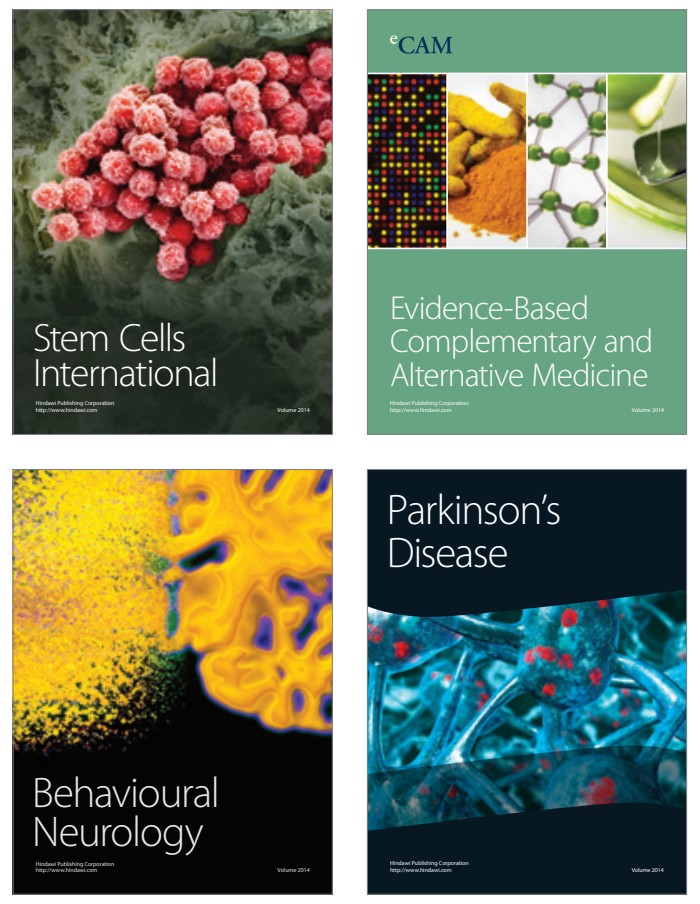
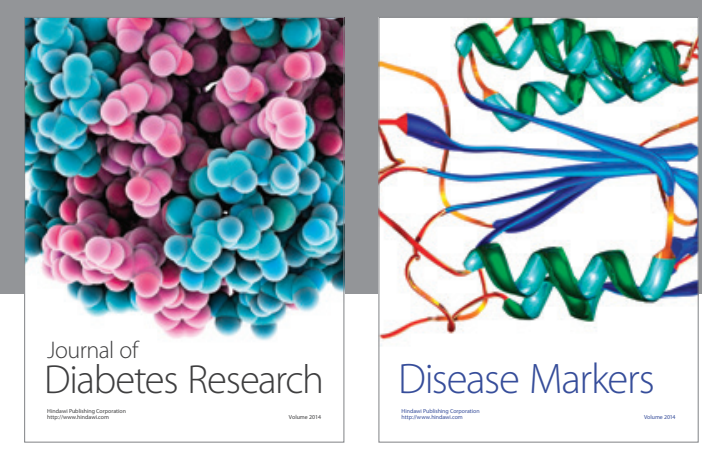

Disease Markers
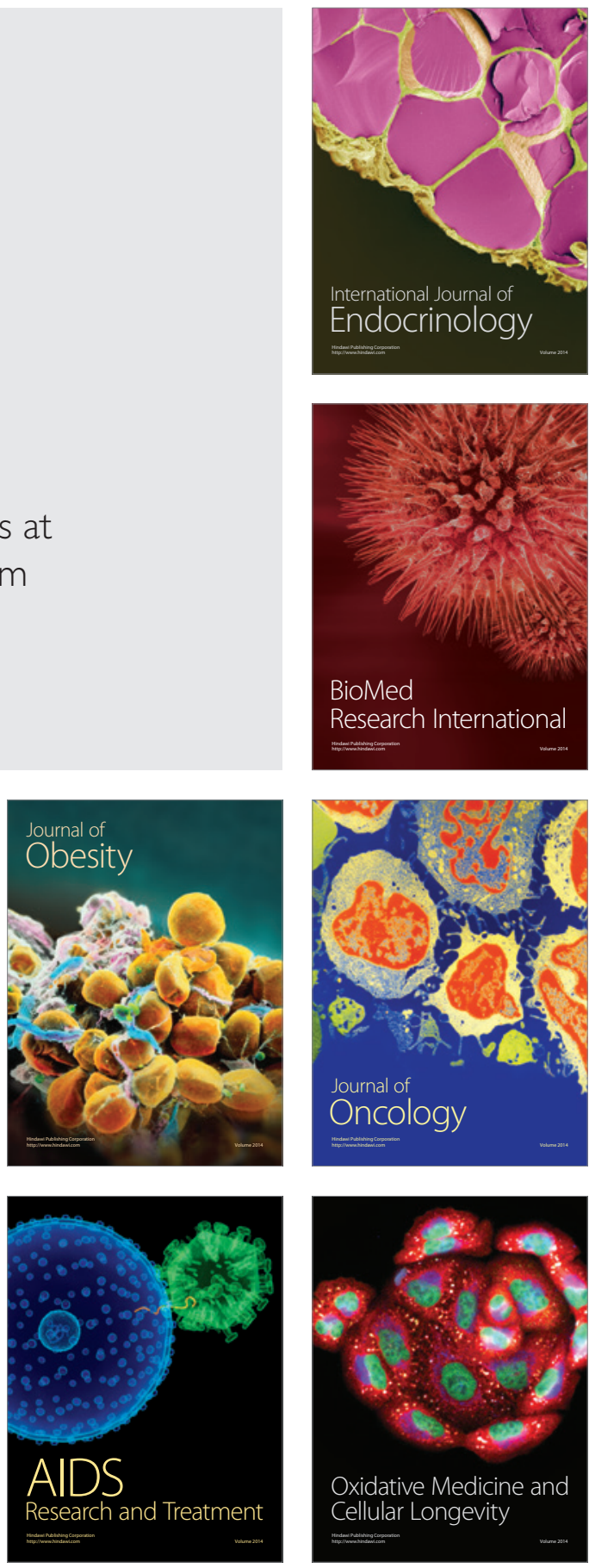